\title{
A TESSITURA DOS ENCONTROS DA REDE DE ATENÇÃO PSICOSSOCIAL
}

\author{
THE FRAMEWORK OF NETWORK FOR PSYCHOSOCIAL CARE MEETINGS
}

LA TESITURA DE LOS ENCUENTROS DE LA RED DE ATENCIÓN PSICOSOCIAL

Loiva dos Santos Leite ${ }^{1}$

Kátia Bones Rocha ${ }^{2}$

Liliane Maria dos Santos ${ }^{3}$

Resumo Este artigo objetiva descrever e analisar a constituição do fórum dos serviços que compõem a Rede de Atenção Psicossocial no território de uma gerência distrital de saúde da cidade de Porto Alegre, no Rio Grande do Sul. Trata-se de um estudo qualitativo realizado por meio de pesquisa-intervenção no período de março de 2014 a março de 2015. Para a análise deste processo, foi utilizado o diário de campo como instrumento de registros dos encontros dos fóruns realizados e os relatórios de avaliação de seminários de capacitação em saúde mental, desenvolvidos com profissionais da atenção primária em saúde. A composição do fórum, que conta com profissionais de diversos serviços, demarca um processo que visa articular diferentes pontos da Rede de Atenção Psicossocial, promovendo interlocução entre os serviços e a corresponsabilidade pela gestão-execução da atenção em saúde no território. A partir das relações que emergem no espaço do fórum, propõe-se repensar os processos de trabalho, problematizando os fazeres e saberes em saúde, remetendo à Educação Permanente em Saúde como uma importante estratégia nesse cenário. Como resultados iniciais, avalia-se que os encontros mensais dos serviços têm proporcionado espaços de reflexão e, ao mesmo tempo, são propositivos quanto à construção de fluxos e conexões entre trabalho, gestão e Educação Permanente, aspectos considerados indissociáveis no campo da saúde pública.

Palavras-chave rede de atenção psicossocial; fórum da RAPS; educação permanente em saúde; pesquisa-intervenção; saúde mental.
Abstract This paper aims to describe and to analyze the foundation of Forums of the services composing the Network for Psychosocial Care in the territory of a Management District of Porto Alegre, Rio Grande do Sul, Brazil. It is a qualitative study performed with intervention-research from March 2014 to March 2015. To analyze this process, we used field diary as a tool to record the Forums and assessment reports of trainings seminars in mental health, performed with primary healthcare professionals. The Forum arrangement, with professionals of several services, defines a process that aims to join different points in the Network for Psychosocial Care, promoting interlocution among the services and co-responsibility for management-execution of the territory healthcare. From the relations emerged in the Forums, we propose to rethink work processes, questioning the practices and knowledges in health, alluding to Permanent Education in Health as an important strategy in this setting. As initial results, we think the monthly meetings provided reflection spaces and proposed construction of flows and connections among work, management, and Permanent Education, aspects considered inseparable in the public health filed. Keywords network for psychosocial care; network for psychosocial care forums; permanent education in health; intervention-research; mental health. 


\title{
Introdução
}

\author{
O correr da vida embrulha tudo. \\ A vida é assim: esquenta e esfria, \\ aperta e dai afrouxa, \\ sossega e depois desinquieta. \\ o que ela quer da gente é coragem. \\ (Guimarães Rosa, 1994)
}

O percurso da vida é dinâmico: altera de acordo com os caminhos que escolhemos trilhar, ora com mais tranquilidade, ora com mais oscilações. Podemos nos inquietar ou aquietar, como poetizou Guimarães Rosa. No percurso que iremos descrever e analisar neste artigo, e que diz respeito ao campo da saúde mental, optamos por trilhar com nossa inquietação. Cenário denso e de muitas disputas, nos inserimos na saúde mental como trabalhadoras-gestoras-pesquisadoras, vivenciando o desafio de estar nesses lugares com todos os atravessamentos que lhes são peculiares. Não se trata, portanto, de um lugar neutro, mas permeado por ideias, crenças e valores que compõem as práticas sociais e a gestão política de qualquer instituição. Para trilhar esse percurso, entendemos que é preciso superar as dicotomias formuladas e exercidas no cotidiano dos serviços, destacando-se as dicotomias entre o pensar e o executar, o planejamento, a gestão e a avaliação no campo da saúde.

Na saúde mental, as dissonâncias estão presentes e se configuram como parte das resistências ${ }^{4}$ em superar o modelo tradicional de atenção às pessoas com doença mental. A partir das diretrizes da Reforma Psiquiátrica, que se tornou lei no ano de 2001 - lei n. 10.216 -, o cenário de práticas de cuidado em saúde mental vem se transformando gradativamente. Contudo, ainda é possível perceber dificuldades em mudar o modelo de atenção. Mesmo com a criação dos serviços substitutivos ao manicômio, como os Centros de Atenção Psicossocial (CAPS) e as residências terapêuticas, as resistências que encontramos nas práticas de atenção em saúde são expressivas, justamente por estarem atravessadas por desejos, ideologias e interesses inusitados e muitas vezes conflitantes. Além de os serviços não serem em número suficiente para formar uma rede capaz de abarcar as demandas de cuidado em saúde mental, o que já é motivo de críticas à Reforma Psiquiátrica, muitos dos serviços que existem mostram-se resistentes em implantar novas práticas de assistência.

Yasui (2006) refere que a Reforma Psiquiátrica brasileira sempre foi um "campo político por excelência", pois é um lugar de disputas, de confrontos, mas também de alianças e contradições.

Sua proposta de ruptura radical com um determinado modelo de entendimento e de cuidado ao sofrimento humano produziu no seu cotidiano histórico, discursos sobre este sofrer, modos de cuidar e lugares que enunciavam estes mesmos discursos. Discursos que se constituem como campos de saber, de produção de verdades (Yasui, 2006, p. 64-65). 
Nesse contexto, propor mudanças nas estruturas físicas e na concepção de cuidado não é suficiente se as mudanças não se processarem também no campo subjetivo dos atores envolvidos com a saúde mental. Pelbart (1993) instiga sobre a necessidade de desconstruirmos nossos muros internos ou nossos 'manicômios mentais', a fim de que nosso pensamento se torne "permeável à desrazão" (p. 107), favorecendo a relação com os acontecimentos imprevisíveis, tanto no pensar como nas práticas sociais:

Trata-se de não burocratizar o Acaso com causalidades secretas ou cálculos de probabilidade, mas fazer do Acaso um campo de invenção e imprevisibilidade; de não recortar o Desconhecido com o bisturi da racionalidade explicativa. (...). Trata-se, enfim, de um pensamento que não transforma a força em acúmulo, mas em Diferença e intensidade. Isso tudo implica, naturalmente, inventar uma nova relação entre corpo e linguagem, entre a subjetividade e a exterioridade, entre os devires e o social, entre o humano e o inumano, entre a percepção e o invisível, entre o desejo e o pensar. (...) Libertar-se do manicômio mental é isso tudo e muito mais (Pelbart, 1993, p. 107-108).

Entendemos que é preciso ir além do que está preconizado, buscando ferramentas que possam subsidiar outros modos de pensar e conceber saúde e de ampliar os processos dialógicos e transformadores do trabalho. Acreditamos na proposta de consolidar o cuidado integral em saúde, respeitando os direitos humanos, a diversidade e a singularidade de cada situação.

Um caminho possível de ser trilhado é o de problematizar a fragmentação entre teorias e práticas, pois em determinados temas sobre saúde há um afastamento entre quem pensa a teoria e quem executa a prática, consolidando um distanciamento entre o fazer e o saber. Ainda, quem está no cotidiano dos serviços nem sempre acessa a teoria ou o próprio saber que produz a respeito de suas práticas em saúde. Esse contexto dicotômico nos provocou a pensar em meios de fazer as conexões acontecerem.

Nesse contexto, um caminho que propusemos foi a constituição de um espaço que reunisse profissionais da Rede de Atenção Psicossocial (RAPS) de cada território sanitário da cidade. Esse espaço, denominado Fórum da Rede de Atenção Psicossocial (FRAPS), possibilitou criar locais de intercâmbio entre saberes e fazeres, em que a concepção de trabalho e de atenção pode ser ampliada, promovendo referências e contrarreferências éticas, técnicas e políticas da atuação em saúde. Inserimo-nos nesse caminho através da pesquisa-intervenção, articulando campos do conhecimento e das práticas, invariavelmente abrindo espaço para a inclusão da Educação Permanente em Saúde (EP).

A EP, por meio da portaria ministerial n. 198, de 13 de fevereiro de 2004, institui-se como política pública no Brasil. De acordo com a proposta da EP, a aprendizagem deve ter como mote a problematização dos processos de trabalho 
cotidianos, articulando conhecimentos técnicos e experiências adquiridas. Deve levar em conta as "necessidades de saúde das pessoas e das populações, da gestão setorial e do controle social em saúde, que tenham como objetivos a transformação das práticas profissionais e da própria organização do trabalho" (Brasil, 2004, p. 6).

Podemos considerar a EP como uma importante ferramenta para problematizar as práticas em saúde mental no contexto em que nos inserimos, proporcionando a ampliação da concepção sobre o cuidado através do compartilhamento de ações que são desenvolvidas nos serviços da RAPS. Tomamos como pressuposto que é possível construir mudanças nas práticas de cuidado em saúde mental a partir da proposta da EP associada à pesquisa-intervenção.

Com relação à pesquisa-intervenção, podemos dizer que é uma investigação qualitativa (Rocha, 2006) e caracteriza-se pela inserção ativa do pesquisador no campo de pesquisa, de maneira a produzir uma intervenção. Essa modalidade de pesquisa pressupõe uma atitude crítica/inventiva e implicativa/desnaturalizadora, bem como "amplia as condições de um trabalho compartilhado" (Aguiar e Rocha, 2007, p. 661), pois desestabiliza as fronteiras demarcadas entre pesquisados e pesquisador. O campo de pesquisa passa a ser problematizado e outras "dimensões do cotidiano" são investigadas, "instaurando tensão entre representação e expressão, com a perspectiva de dar consistência a novos modos de subjetivação" (Rocha, 2006, p. 171).

Acreditamos, a partir desses aspectos, que a pesquisa-intervenção favorece a ação do pesquisador no campo a ser investigado, por considerar a participação do pesquisador como um ator incluso no cenário, e não como um agente externo. Descaracteriza a suposta neutralidade de quem investiga algo para constituir o pesquisador como parte do processo de construção do fazer-saber.

\section{Percurso metodológico}

Este artigo apresenta parte da pesquisa realizada com profissionais e gestores da RAPS da Secretaria Municipal da Saúde de Porto Alegre, Rio Grande do Sul, para a tese de doutorado em Psicologia Social denominada Educação Permanente em Saúde: uma estratégia para transformar práticas em saúde mental, de autoria da primeira autora. É um estudo de abordagem qualitativa e toma como referência o processo de constituição do Fórum da Rede de Atenção Psicossocial em uma gerência distrital de saúde (GD) da cidade de Porto Alegre. Fizeram parte do FRAPS os profissionais dos serviços do território da GD, a gerente distrital - no papel de gestora do território - e a coordenadora da área técnica de saúde mental da Secretaria Municipal da Saúde - representando a política de saúde mental e, nesse contexto, também como pesquisadora.

O estudo apresentado neste artigo se configura como uma pesquisa-intervenção, pois retrata a inserção das pesquisadoras no campo investigado 
através da participação ativa na configuração do Fórum, como integrantes e como propositoras desse espaço. A pesquisa-intervenção, como sua designação situa, trata-se de uma modalidade de pesquisa em que o pesquisador se insere no campo a ser investigado e produz uma intervenção, contribuindo para a transformação da realidade. Nessa proposta, é necessário considerar o contexto sócio-histórico para analisar as práticas e os discursos que permeiam as relações, evidenciando a ideologia dominante, bem como as relações de saber-poder. Segundo Rocha e Aguiar (2003, p. 67), o caráter desnaturalizador e desestabilizador da pesquisa-intervenção se expressa na substituição da fórmula "conhecer para transformar" por "transformar para conhecer", possibilitando a ação transformadora tanto no nível micro como macropolítico.

Para análise deste processo utilizou-se a ferramenta diário de campo, elaborado a partir dos registros dos FRAPS, que são realizados mensalmente, com a duração aproximada de quatro horas, totalizando 12 encontros no período de um ano (março de 2014 a março de 2015), com uma média de participação de 25 profissionais. O diário de campo favorece registros de situações e sensações, tanto de maneira descritiva como reflexiva. Permite evidenciar o "olhar particular" do pesquisador acerca do que está sendo pesquisado, portanto, "carregado da subjetividade" de quem registra (Pinho e Molon, 2011, p. 4).

Também usamos os relatórios de avaliação de seminários de capacitação em saúde mental, realizados com profissionais da atenção básica em saúde. Os participantes responderam a uma avaliação dos encontros por meio de um questionário com questões fechadas e abertas, compiladas e organizadas por temas. As questões se referiam às expectativas em relação ao curso; se os conteúdos abordados contemplaram as necessidades vivenciadas no cotidiano do trabalho em saúde; se houve espaço para discussões; se a metodologia utilizada possibilitou discussões e reflexões; se os profissionais se sentiam aptos para atender pessoas com problemas relativos à saúde mental após a capacitação. Foram analisados dois relatórios avaliativos, elaborados com as respostas de 53 participantes, de um total de 65 profissionais que concluíram os cursos.

Para apreciação do material, utilizamos a análise temática proposta por Braun e Clarke (2006), por ser um método útil para trabalhar com o paradigma da pesquisa participativa, favorecendo a obtenção de dados para produção de análises qualitativas e adequadas para nortear o desenvolvimento de políticas.

Os participantes assinaram o termo de consentimento livre e esclarecido e os critérios éticos foram respeitados, de acordo com a resolução n. 466/2012, sobre Pesquisa com Seres Humanos, do Conselho Nacional de Saúde (Brasil, 2013). O sigilo quanto à identidade dos participantes foi preservado. O estudo foi aprovado pelos Comitês de Ética em Pesquisa da Pontifícia Universidade Católica do Rio Grande do Sul e da Prefeitura Municipal de Porto Alegre, com o parecer número 772.469 . 


\section{A constituição do Fórum da Rede de Atenção Psicossocial}

A Política Nacional de Saúde Mental, com a publicação da portaria n. 3.088/2011, estabelece e propõe diretrizes para a consolidação da RAPS. A Rede tem como um de seus pressupostos a articulação dos diferentes pontos de atenção para as pessoas com sofrimento ou transtorno mental e com necessidades decorrentes do uso de crack, álcool e outras drogas, no âmbito do Sistema Único de Saúde (SUS) (Brasil, 2011).

Atendendo ao pressuposto referido na portaria, a GD, junto com a Área Técnica de Saúde Mental da Secretaria Municipal de Saúde (SMS), constituiu, em setembro de 2013, um fórum com o objetivo de proporcionar um espaço permanente de diálogo entre os serviços que compõem a RAPS do território. Constituem esse espaço: os Centros de Atendimento Psicossocial, a Equipe de Saúde Mental Adulto, o Residencial Terapêutico, o Centro de Testagem e Aconselhamento em DST/Aids, o Núcleo de Apoio à Saúde da Família, a Equipe Especializada em Saúde da Criança/Adolescente e o Plantão de Saúde Mental. Participam também a Fundação de Assistência Socioeducativa, a Assistência Social, além de professores e alunos do programa do PET-UFRGS, estagiários e residentes das diversas áreas da saúde da Universidade Federal do Rio Grande do Sul. Este fórum é coordenado pela GD e pela coordenadora da Área Técnica da Política de Saúde Mental da SMS.

A composição desse espaço demarca um processo que visa articular os diferentes pontos de atenção da RAPS no território, promovendo a interlocução entre os serviços. Porém, para além da interlocução, entendemos que é estratégico que os profissionais participem dos processos de trabalho, configurando a corresponsabilidade pela gestão-execução da atenção em saúde. Nesse sentido, este espaço favorece a ampliação das perspectivas diante das diferenças, dos conflitos e dos interesses que emergem no contexto de trabalho e, em alguma medida, o alinhamento dos fazeres em saúde.

Entendemos que o campo de atuação em saúde mental requer o uso de tecnologias leves, conforme descrevem Merhy e Franco (2003). As tecnologias leves estão no âmbito da relação que se estabelece entre profissional e usuário ou mesmo entre os profissionais. A capacidade de escutar, de interagir e de realizar um "trabalho vivo (...) em ato" potencializam ações de cuidado integral e de saúde (Merhy e Franco, 2003, p. 6-7). Na atenção em saúde mental, o uso das tecnologias leves nos remete ao campo relacional, acolhendo o usuário e suas demandas e estabelecendo vínculos que promovem a responsabilização e mudanças no "núcleo tecnológico do cuidado" (Merhy e Franco, 2003, p. 9).

Essa direção nos leva a pensar que a atuação dos profissionais no campo da saúde exige investimento permanente na qualificação, e que as técnicas de cuidado e atenção dependem diretamente do fazer. Para além dos equipamentos tecnológicos que são utilizados nos tratamentos em saúde, é a ação realizada pelo sujeito-profissional que vai configurar, em muitas situações, a resolutividade ou 
qualidade do atendimento em saúde mental, já que a tecnologia do cuidado em saúde mental requer o envolvimento diferenciado por parte dos trabalhadores, não somente a partir da oferta de medicação e internação, mas da vinculação. A lógica de atendimento não pode ser centrada na doença mental, mas na pessoa que ali está, com sua singularidade, diferenças e demandas específicas. Isso, ao mesmo tempo em que complexifica o trabalho, favorece a criação de vínculo e a possibilidade de integralidade da atenção em saúde (Leite, 2012).

Diante dessa perspectiva, precisamos de estratégias para integrar e viabilizar o diálogo entre os trabalhadores, gestores, usuários, familiares, instituições de ensino e todos os envolvidos na atenção em saúde. Estratégias que permitam circular os afetos, compartilhar as diferenças e as dificuldades que se impõem no cotidiano do cuidado e, ao mesmo tempo, buscar as mudanças necessárias no fazer em saúde. Sabemos que as mudanças nos processos de trabalho são inevitáveis e provocam inúmeras reações nos profissionais e usuários. Porém, compartilhar as vicissitudes que advêm dessas transformações pode auxiliar a minimizar as resistências. Nesse aspecto, consideramos que o FRAPS constitui um espaço que tem possibilitado conexões e transformado o desenho da cartografia do território. Ao mesmo tempo, podemos acompanhar os "percursos, implicação em processos de produção, conexão de redes e rizomas" (Passos, Kastrup e Escóssia, 2015, p. 10) que configuram o fazer em saúde.

Segundo Deleuze e Guattari (2011), o rizoma configura-se por linhas que podem ser rompidas, reconfiguradas, desfeitas e retomadas de qualquer parte, não havendo uma conformação estanque. Isso nos leva a pensar nas possibilidades de invenção e nos diversos caminhos que podem ser trilhados na medida em que acontecem os encontros da RAPS. Porém, como já assinala uma perspectiva rizomática, não temos respostas prontas, nem tampouco um método que nos indique o caminho, ou seja, estamos em pleno percurso de descoberta e indagações. Estamos tateando, experimentando e observando alguns efeitos do que provocamos e do que nos provoca cada movimento, cada ação ou inércia. Nós nos aventuramos a inventar e propor coletivamente algumas possibilidades de 'trans-formações' no que estamos habitualmente acostumados a viver na saúde mental, com abertura ao diálogo franco e objetivo entre os participantes.

Avaliamos que os FRAPS se potencializaram como um espaço de diálogo entre os diferentes serviços que o compõe, buscando, nos encontros mensais, realizar as conexões entre eles, tecendo o que podemos chamar de rede aquecida (Passos e Benevides, 2004) e flexível às demandas dos usuários. “Rede é uma construção permanente, processual, precisa estar contextualizada com as demandas. Trata-se de um exercício no campo das políticas públicas" (Diário de campo).

Ao abrir espaços para compartilhar a diversidade no FRAPS, seja de conhecimentos ou concepções, proporciona-se a democratização das relações de trabalho, pois o trabalho vivo (Merhy e Franco, 2003) pressupõe um coletivo de profissionais participativos e corresponsáveis. Para Escóssia e Kastrup (2005, p. 303), 
os coletivos podem ser compreendidos como redes que se configuram no agenciamento ${ }^{5}$ das relações que se produzem entre os indivíduos e no coengendramento destes com a sociedade. As redes que compõem os coletivos são resultado de "processos de composições e associações" que reverberam em formas provisórias, híbridas e mutantes, com "capacidade de relançar constantemente sua própria ação" (Escóssia e Kastrup, 2005, p. 302).

Kastrup e Passos (2013, p. 266) referem que coletivo pode ser entendido como uma grupalidade que avança "para além das dicotomias das formas hegemônicas de organização", desestabilizando as fronteiras disciplinares de modo a potencializar e incluir as diferenças. Destacam que o coletivo não pode ser reduzido à soma dos indivíduos ou ao que resulta do encontro entre os mesmos; coletivo é concebido como "rede de composição potencialmente ilimitada de seres tomados na proliferação das forças de produção de realidade" (Kastrup e Passos, 2013, p. 270).

Nesse sentido, entendemos o FRAPS como espaço de Educação Permanente, com possibilidades de avançar na problematização do processo e das características do trabalho realizado, identificando "as necessidades de qualificação, garantindo a aplicabilidade e a relevância dos conteúdos e tecnologias estabelecidas", como expressam Ceccim e Feuerwerker (2004, p. 50).

\section{Fórum da RAPS: espaço de Educação Permanente em Saúde}

A constituição do FRAPS da GD apresentou-se como uma importante estratégia de intervenção na gestão dos serviços de saúde do território. Buscamos, neste espaço, ativar os agenciamentos manifestados e produzidos, descortinando o instituído na busca do instituinte. Instituído e instituinte coexistem no mesmo plano de forças, atravessando a vida cotidiana e as relações sociais, ora de maneira mais conservadora - instituído - ora de maneira mais revolucionária e inovadora - instituinte (Romagnoli, 2014).

Contudo, em muitos momentos é perceptível a manutenção dos processos burocráticos, como registrado no diário de campo:

(...) ficamos pensando o quanto as pessoas/profissionais se autorizam a burocratizar a vida, especialmente no âmbito do trabalho, na rede pública. Isso parece, de alguma maneira, eximi-las de um envolvimento com o processo de cuidado e reafirmar uma tendência a dizer 'não' de imediato. Ou seja, quanto mais dificultamos as coisas, menos as pessoas nos acessam. Logo, nos confortamos nesse lugar de inércia (Diário de campo).

Nos nossos cotidianos de trabalho, percebemos o quanto é difícil fugir da lógica instituída e produzir linhas de fuga ou brechas por onde outras possibilidades de fazeres, saberes e viveres possam passar. Estamos tão imersos e capturados pela lógica instituída que até a crítica perde potência, muitas vezes 
nos enfraquecendo e nos acomodando. Não raro, nos colocamos no lugar de espectadores e aguardamos pelo outro ou por alguém que possa nos 'tirar' desse lugar, ou, ainda, vivemos reproduzindo modelos sem nos desacomodarmos ou incomodarmos. Entretanto, o FRAPS vem ao encontro de pensar-problematizar o incômodo que nos atravessa e que persiste na medida em que começamos a tensionar sobre o sentido dos fazeres em saúde, especialmente no âmbito da saúde mental. No registro do diário de campo identificamos a relevância dos encontros no FRAPS:

Os encontros de profissionais possibilitam o diálogo, as trocas de informações, a constituição de rede ou mesmo o "aquecimento" da rede, favorecendo a fluidez do trabalho. Aqui podemos pensar na tecnologia leve de Merhy, ou seja, é relacional, em muitos momentos, pois é através do contato com meu colega que fortaleço, estabeleço, reconheço e invisto no meu processo de trabalho. Isso porque encontro no outro muitos aspectos semelhantes aos meus, à minha rotina, demandas e fazeres. E quando os profissionais conseguem encontrar sentido para o conhecimento, sentem-se à vontade para falar, expressar o que pensam e vivem no trabalho em saúde (Diário de campo).

Para a organização desses encontros, estabeleceu-se um cronograma de reuniões mensais em que a pauta era construída a cada encontro, a partir da problematização e necessidade apresentada pelos participantes. A partir da problematização das questões que os profissionais traziam, identificamos os 'nós' críticos e partimos em busca de estratégias de intervenção. Nesse viés, o fórum se constituiu como espaço de EP, no qual buscamos uma dimensão pedagógica, além de se configurar, como já afirmamos, como uma potente estratégia de gestão.

Ceccim (2005b) destaca que

aquilo que deve ser central à Educação Permanente em saúde é sua porosidade à realidade mutável e mutante das ações e dos serviços, introdução de mecanismos, espaços e temas que geram autoanálise, autogestão, implicação, mudança institucional, enfim, pensamento (disruptura com instituídos, fórmulas ou modelos) e experimentação (em contexto, em afetividade - sendo afetado pela realidade/ afeç̧ão) (Ceccim, 2005b, p. 162).

A EP pode ser caracterizada como um processo que coloca em análise o cotidiano do trabalho em saúde, examinando as relações que acontecem nos espaços institucionais, a realidade na qual se inserem, e "os sentidos dos atos produzidos" (Ceccim, 2005b, p. 161). A EP leva a operar mudanças no campo da saúde, incidindo na concepção de modelos de atenção e na gestão do sistema de saúde, ampliando a noção de saúde e de cuidado e transcendendo a lógica de atenção, ainda muito direcionada para a doença. Desse modo, a concepção de integralidade 
no cuidado em saúde toma uma dimensão estratégica para responder às demandas em saúde e não pode estar desvinculada de qualquer aprendizagem nesse campo.

Para Haddad, Roschke e Davini (1990), o conceito de Educação Permanente em Saúde

busca alternativas e soluções para os problemas reais e concretos do trabalho habitual privilegiando o processo de trabalho como eixo central da aprendizagem e enfatizando a capacidade humana de criar conhecimento novo, a partir da discussão e análise conjuntas e participativas dos problemas reais, de suas causas e das implicações que as alternativas de solução têm na busca da transformação da prática de saúde, objetivo essencial do ato educativo (Haddad, Roschke e Davini, 1990, p. 136-137).

Os FRAPS proporcionaram espaço de reflexão, de intersecções de pensamentos acerca do trabalho, de EP e gestão em saúde. Acreditamos que estes encontros constituem um dispositivo que viabiliza o exercício de pensar e de movimentar-se para diferentes caminhos. Tem sido possível problematizar, aprender, construir, fazer e desfazer passos em um processo recursivo. A cada movimento, as conexões vão se reestabelecendo como na constituição de um mapa “aberto, comentável em todas as suas dimensões, desmontável, reversível, suscetível de receber modificações constantemente" (Deleuze e Guattari, 2011 , p. 30). Assim, percebemos os FRAPS em movimento incessante, como uma coreografia que se configura em processo, no fazer cotidiano em saúde.

Acreditamos que esse é um espaço de EP potencial, pois é no contexto do trabalho, nesse cotidiano da atenção que podem se produzir problematizações, tensões, reflexão crítica, mudanças e desacomodação. Não é uma tarefa fácil acompanhar esses processos, pois a energia parece se esgotar, mas também é muito gratificante quando começamos a perceber os resultados (Diário de campo).

Nas discussões, foi possível observar o envolvimento dos profissionais e coordenadores dos diversos serviços, assim como os consensos, os dissensos e as diversas situações que compõem a construção da RAPS. Dentre estas, destacamos as potencialidades que advêm da especificidade de cada serviço, a necessidade de adequar-se às mudanças no modo de viver contemporâneo, a busca por maior resolutividade nos serviços prestados à comunidade, o vínculo com os usuários e a crescente demanda de atenção no campo da saúde mental.

A realização dos FRAPS possibilitou compartilhar conhecimentos entre os participantes. Diversos questionamentos foram trazidos pelos profissionais, tendo em vista as práticas efetivadas no cotidiano das políticas públicas, da realidade de cada serviço, das vulnerabilidades vividas pela população. Por esse processo, percebemos que muitas inquietações vivenciadas nesse coletivo reverberaram no cotidiano do fazer em saúde. Diante disso, alguns questionamentos foram 
levantados pelos profissionais no FRAPS: o quanto o fórum da RAPS tem contribuído nos processos de trabalho para produção de ações instituintes? Como são operados os dispositivos que viabilizam vida? Como os agenciamentos potentes se produzem no cotidiano? Quais configurações são possíveis?

Acreditamos que as respostas não são simples e que não há receitas e prescrições para a complexidade que envolve o cuidado em saúde, especialmente em saúde mental. Tampouco podemos responder imediatamente a todas as questões, mas iniciamos um percurso e descobrimos algumas pistas que podem nos conduzir nesse trajeto a ser investigado. "As pistas que guiam o cartógrafo são como referências que concorrem para a manutenção de uma atitude de abertura ao que vai se produzindo e de calibragem do caminhar no próprio percurso da pesquisa" (Passos, Kastrup e Escóssia, 2015, p. 13).

Uma pista que se anunciou foi a demanda por capacitação em saúde mental para profissionais da Atenção Primária do território da GD, seguindo a concepção da EP. Consideramos essa possibilidade uma abertura estratégica por onde poderíamos inserir o tema do cuidado em saúde mental no fazer cotidiano da atenção básica e "romper com os muros estigmatizantes" (Scarparo, Leite e Santos, 2013, p. 143) que cercam a doença mental. Buscamos realizar a capacitação baseada nos princípios da EP, pois "além de investir no conhecimento individual" sobre determinado tema, favorece a participação dos profissionais no enfrentamento dos problemas vivenciados pela equipe, sublinham Vivot e Osório (2013, p. 437).

\section{Saúde mental e atenção básica: visibilizando e ampliando conexões}

Os caminhos que trilhamos na saúde mental são rizomáticos; há diversas possibilidades de conexões, pois cada pessoa é singular e os encontros que se produzem são distintos, fugindo da lógica linear e homogênea do cuidado protocolar. No espaço do FRAPS, buscávamos justamente desestabilizar a linearidade instituída nos cotidianos de trabalho que engessam os fazeres em saúde. Visávamos constituir um espaço em que fosse possível tecer redes em permanente construção, abertas e com múltiplas entradas. Nessa perspectiva, vamos relatar uma atividade que se configurou a partir da aproximação dos profissionais dos serviços de saúde mental com atenção básica, em espaços de matriciamento e do FRAPS. A atividade refere-se à organização de um espaço de capacitação em saúde mental para os profissionais que atuam na atenção básica, porta de acesso preferencial para os usuários do SUS. Os profissionais da atenção básica manifestaram o desejo e a necessidade de ampliar conhecimentos sobre o cuidado em saúde mental, visto que no cotidiano de trabalho recebem uma demanda expressiva de pessoas com problemas de saúde mental.

Atualmente, um número significativo de usuários do SUS que acessam as unidades de saúde e que apresentam demandas de saúde mental são en- 
caminhados para outros componentes estratégicos da RAPS, como os CAPS. Contudo, Figueiredo e Campos (2009) referem que cerca de $80 \%$ das pessoas que são encaminhadas para serviços de saúde mental não têm uma demanda específica que justifique essa necessidade. Assim, a dicotomia entre corpo e mente, tão arraigada na nossa cultura e nas ações de cuidado, entra em pauta nos processos de trabalho dos serviços da rede básica de saúde, evidenciando a premência de pensar a integralidade da atenção.

No contexto do FRAPS, os profissionais com pouca experiência e conhecimentos em saúde mental sentiram necessidade de efetivar práticas que dessem conta de suas interrogações e das demandas dos usuários que chegavam à atenção básica. Para isso, foram organizados seis encontros, de quatro horas cada, dirigidos aos profissionais médicos e enfermeiros que atuam nas diversas unidades de saúde do território. Para favorecer a interface entre os níveis de complexidade do cuidado em saúde, foram convidados os profissionais dos diferentes componentes da RAPS do território para ministrar os encontros psiquiatras, pediatras, enfermeiras e psicólogas.

Essa interface contribuiu para que os serviços que compõem a RAPS dialogassem e levassem para os seminários os entraves que atravessam o cotidiano de trabalho e, a partir desse diálogo, pudéssemos compor estratégias a serem colocadas em prática, como expressa uma profissional que participou dos seminários: "Aqui foram trazidas situações reais que geraram discussões importantes para conseguirmos ver as diferentes formas de atuação e chegarmos numa melhor forma de atendimento" (sic).

Ceccim (2005a) refere que os espaços coletivos em que a formulação e a execução do trabalho em saúde estão organizados com menor separação favorecem uma auto-organização que valoriza a experiência, assim como

a produção de protagonismo, compromisso e responsabilidade, esses coletivos organizados podem propor projetos de invenção de saúde e de reprodução social das existências; trata-se de utilizar a riqueza infinita dos papéis sociais possíveis, mas também, promover ativamente essas possibilidades (Ceccim, 2005a, p. 172).

Como pontua o autor, é no cotidiano que se produzem as experiências coletivas e é viabilizando espaços dialógicos com os atores envolvidos nos processos de atenção à saúde que iremos reinventar os modos de produzir saúde. Possibilitar este espaço coletivo dos serviços que compõem a RAPS, oportunizando compartilhar, problematizar, desvelar as tensões e os conflitos que emergem nas equipes é uma tarefa desafiadora para a gestão da atenção em saúde. Gestão, nesse contexto, não se refere apenas à organização do processo de trabalho, mas se configura a partir do protagonismo dos atores envolvidos com o cuidado em saúde. Barros e Barros (2007) escrevem: 
(...) a gestão em saúde terá (e tem) de passar, necessariamente, pela problematização das escolhas que fazemos de como lidar com o que constitui, a nosso ver, como vetores-dobras inseparáveis do campo da saúde: sujeitos (desejos, necessidades, interesses), processos de trabalho (saberes), poder (modos de estabelecer as relações) e políticas públicas (coletivização dessas relações) (Barros e Barros, 2007, p. 62).

No percurso da capacitação, vários temas foram abordados, provocando discussões e problematizações acerca do processo de trabalho das equipes. Utilizamos situações e estudos de casos vivenciados pelos profissionais da atenção básica, o que potencializou falas, escutas e sensibilizou o olhar, como referiu uma das participantes: "Como na nossa rotina temos muitos casos de saúde mental, essa capacitação trouxe um olhar mais voltado para esses casos, um acolhimento, uma escuta mais qualificada e isso, consequentemente, auxilia no nosso processo de trabalho".

Sobre a importância de constituir espaços de diálogo que aproxime a teoria da prática dos serviços, registramos no diário de campo:

Participantes ativos interagem, respondem aos questionamentos e trazem exemplos do cotidiano de trabalho. A metodologia que foi utilizada pela psiquiatra aproximou o teórico da prática e isso gerou muitas falas dos participantes, que se sentiram próximos do que ela estava explanando (Diário de campo).

As discussões de casos e exemplos cotidianos se mostraram importante ferramenta de qualificação dos processos de trabalho, pois retratam aspectos da realidade dos profissionais, o que provoca uma aproximação entre o fazer-saber como referiu uma integrante do curso: "A ideia das discussões de casos, a aproximação da realidade nos permitiu escutar, falar, dividir as angústias e conhecer o outro lado (a referência)". Ou, ainda: “Muito efetiva, pois nos transporta o tempo todo para a realidade, para vivências, para enxergar melhor cada caso e tentar observar vários aspectos das situações que vivenciamos, seja profissionalmente ou pessoalmente".

Os profissionais da atenção básica mostraram-se participantes ativos, interessados e trouxeram exemplos das vivências do cotidiano de trabalho. Possuem um volume imenso de trabalho, numa realidade muito difícil, em contextos de pobreza, violências e negligências. Tudo isso faz parte do dia a dia dos serviços de saúde, e os profissionais demonstram compromisso social (Dimenstein, 2001) e envolvimento com as comunidades em que atuam.

Não raro, a imersão contemporânea na cultura da urgência nos leva a buscar respostas imediatas, resolutivas e sem muita reflexão (Bauman, 2000). Isso, no campo da saúde, faz com que se acentuem os diagnósticos e o uso de medicação para o que, às vezes, é apenas efeito de determinada situação, como um luto, por exemplo, e a lógica dos serviços é dar respostas também 
imediatas e prescritivas. Precisamos ter cuidado para não cairmos na tentação de resolver de maneira simplista e esvaziar de sentido o que pode ser produção de outros significados para determinados momentos da existência.

Nesse contexto, mudar o modelo de atenção em saúde trata-se de um desafio que implica também questionar a rapidez com que se processam as relações. Isso requer a problematização dos processos de trabalho, o que pode ser feito em espaços de EP, em que as situações e a maneira como as conduzimos são analisadas. As mudanças, por sua vez, exigem novas formas de abordagem e atendimento aos usuários, o que faz com que os trabalhadores solicitem "a continuidade das discussões com periodicidade", como colocou um dos participantes.

Com os FRAPS, temos a pretensão de constituir um espaço de problematização e de análise das demandas em saúde que estão sendo delineadas a partir dos modos de viver contemporâneos. Há a necessidade, nesse contexto, de repensar as práticas em saúde, seja por parte dos profissionais, seja pelos gestores, assim como há necessidade de repensar a relação dos profissionais com o cuidado realizado aos usuários. Buscamos ainda, através dos FRAPS, impulsionar uma conjunção de forças suficiente para desconstituir a norma, a regra, transgredir conceitos e práticas cristalizadas, borrar as especialidades, romper as fronteiras e estabelecer a constituição de "um rizoma, [o qual] não começa nem conclui, ele se encontra sempre no meio, entre as coisas, inter-ser, intermezzo", como escreveram Deleuze e Guattari (2011, p. 48).

\section{Considerações finais}

A inquietação que o trabalho no campo da saúde mental nos provocou foi estratégica para que propuséssemos a constituição do Fórum da RAPS no território da GD. Buscávamos movimentar os fazeres e saberes em saúde para além do que estava posto como norma ou rotina de trabalho já instituídas. Pretendíamos compartilhar a inquietação que nos atravessava com os demais profissionais e, nesse processo, problematizar o trabalho realizado nos cotidianos dos serviços. Nesse percurso, propomos o FRAPS e iniciamos a inquietação coletiva, ora com mais, ora com menos força. Tivemos momentos de discussões acaloradas, outros nem tanto. Entretanto, o espaço estava se consolidando por meio de uma tessitura singular, respeitando o tempo e as características dos profissionais e serviços que compunham o FRAPS, numa composição que abarcava a contradição e a dialogicidade, superando a hierarquia verticalizada de inúmeros processos de trabalho que se reproduzem institucionalmente.

Contudo, é um processo em permanente construção, pois horizontalizar as relações de trabalho entre profissionais e gestores era - e ainda é - uma direção a ser seguida e uma resposta a ser alcançada. Aqui reside a importância da EP como ferramenta estratégica para trabalhar a superação do modelo assistencial centrado no especialismo, na fragmentação de saberes e poderes e 
na conduta prescritiva e protocolar, não raro distante da realidade das pessoas e de seus contextos de vida. Nesse aspecto, a saúde mental ainda tem muito a aprender com a atenção básica, visto que esta possui uma vasta trajetória no cuidado realizado no território, próximo das pessoas e dos lugares onde vivem.

Os seminários de capacitação em saúde mental para profissionais da atenção básica foram estratégicos nesse aspecto, pois revelaram o quanto essa interface pode ampliar o cuidado integral em saúde, agregando conhecimentos, trajetórias e, com isso, corresponsabilizando profissionais e usuários no cuidado em saúde.

Percebemos, com a sequência sistemática de encontros, que os FRAPS proporcionaram espaços de reflexão e, ao mesmo tempo, foram propositivos quanto à construção de fluxos e conexões entre trabalho, gestão e EP, aspectos que consideramos indissociáveis no campo da saúde pública.

Olhar para o território e para as relações que dele emergem, bem como pensar a organização e seus processos de trabalho são desafios constantes na gestão e execução do trabalho, remetendo invariavelmente à EP. Isso se dá justamente porque não há um modelo generalista e consolidado a ser seguido, mas sim possibilidades de se construir coletivamente a atenção em saúde, de acordo com as demandas de cada território onde a vida das pessoas acontece. Por isso, é importante viabilizar espaços no mundo do trabalho que possibilitem diálogos entre gestores, trabalhadores, equipes, estudantes, instituições e a comunidade que habita o território, o que nos indica a necessidade de constituir um coletivo implicado com o ato pedagógico de produção de saúde.

As inquietações não podem parar; precisam nos estimular para movimentar a RAPS em caminhos que se reconfiguram permanentemente, que nos apertam e nos soltam. Como escreveu o poeta Guimarães Rosa, o que a vida quer da gente é coragem.

Resumen El objetivo del presente estudio es describir y analizar la constitución del foro de los servicios que componen la Red de Atención Psicosocial (RAPS) en el territorio de una gerencia distrital de salud de la ciudad de Porto Alegre, Rio Grande do Sul, Brasil. Se trata de un estudio cualitativo realizado por medio de investigación-intervención en el período de marzo de 2014 a marzo de 2015. Para el análisis de este proceso, se utilizó el diario de campo como instrumento de registro de los encuentros de los foros realizados y los informes de evaluación de seminarios de capacitación en salud mental, realizados con profesionales de la atención primaria en salud. La composición del foro, que cuenta con profesionales de diversos servicios, demarca un proceso que busca articular diferentes puntos de la Red de Atención Psicosocial, promoviendo interlocución entre los servicios y la corresponsabilidad por la gestión-ejecución de la atención en salud en el territorio. A partir de las relaciones que emergen en el espacio del foro, se propone repensar los procesos de trabajo, problematizando el hacer y los saberes en salud, remitiendo a la Educación Permanente en Salud como una importante estrategia en ese escenario. Como resultados iniciales, se evalúa que los encuentros mensuales de los servicios han proporcionado espacios de reflexión y, al mismo tiempo, son propositivos en cuanto a la construcción de flujos y conexiones entre trabajo, gestión y Educación Permanente, aspectos considerados indisociables en el campo de la salud pública.

Palabras-clave red de atención psicosocial; foro de RAPS; educación permanente en salud; intervención-investigación; salud mental. 


\section{Notas}

${ }^{1}$ Prefeitura Municipal de Porto Alegre, Secretaria Municipal da Saúde de Porto Alegre, Rio Grande do Sul, Brasil.

$<$ loivaleite.psi@gmail.com>

Correspondência: Avenida Capivari, 2410. Bairro: Santa Tereza. Porto Alegre/RS. CEP 90810070.

${ }^{2}$ Pontifícia Universidade Católica do Rio Grande do Sul, Programa de Pós-Graduação em Psicologia, Porto Alegre, Rio Grande do Sul, Brasil.

$<$ katiabonesrocha@gmail.com>

${ }^{3}$ Prefeitura Municipal de Porto Alegre, Secretaria Municipal da Saúde de Porto Alegre, Rio Grande do Sul, Brasil.

$<$ lilianesantos17@gmail.com>

${ }^{4}$ No sentido que utilizamos no texto, tomamos resistência por movimento ou força em oposição ao que se evidencia como mudança ao instituído, ao que está posto, a norma vigente. Podemos considerar como uma reação para preservar o que existe.

5 "Agenciar é estar no meio, sobre a linha de encontro de dois mundos. Agenciar-se com alguém, com um animal, com uma coisa - uma máquina, por exemplo - não é substituí-lo, imitá-lo ou identificar-se com ele: é criar algo que não está nem em você nem no outro, mas entre os dois, neste espaço-tempo comum, impessoal e partilhável que todo agenciamento coletivo revela" (Escóssia e Kastrup, 2005, p. 303).

\section{Referências}

AGUIAR, Katia F.; ROCHA, Marisa L. Micropolítica e o exercício da pesquisa-intervenção: referenciais e dispositivos em análise. Psicologia, Ciência e Profissão, Brasília, v. 27, n. 4, p. 648-663, 2007. Disponível em: <doi: 10.1590/S1414-98932007000400007>. Acesso em: 21 jul. 2015

BAUMAN, Zygmunt. Em busca da politica. Rio de Janeiro: Zahar Editores, 2000.

BARROS, Regina D. B.; BARROS, Maria E. Barros. Da dor ao prazer no trabalho. In: SANTOS-FILHO, Serafim; BARROS, Maria E. Barros (orgs.). Trabalhador da saúde: muito prazer! Protagonismo dos trabalhadores na gestão do trabalho em saúde. Ijuí: Editora Unijuí, 2007. p. 61-71.
BRASIL. Ministério da Saúde. Portaria GM/ MS n. 198, de 13 de fevereiro de 2004. Institui a Política Nacional de Educação Permanente em Saúde como estratégia do Sistema Único de Saúde para a formação e o desenvolvimento de trabalhadores para o setor e dá outras providências. Brasília: Ministério da Saúde, 2004. Diário Oficial da União, Brasília, DF, n. 32, 13 fev. 2004.Seçãol, p. 37-41.

BRASIL. Ministério da Saúde. Portaria n. 3.088, de 23 de dezembro de 2011. Institui a Rede de Atenção Psicossocial para pessoas com sofrimento ou transtorno mental e com necessidades decorrentes do uso de crack, álcool e outras drogas, no âmbito do Sistema Único de Saúde (SUS). Diário Oficial da União, Brasília, DF, 26 dez. 2011 . Seção 1, p. 230-232. 
BRASIL. Conselho Nacional de Saúde. Resolução n. 466/2012. Diretrizes e Normas regulamentadoras de pesquisa envolvendo seres humanos. Diário Oficial da União, Brasília, DF, 13 jun. 2013, Seção 1, p. 59.

BRAUN, Virginia; CLARKE, Victoria. Using thematic analysis in psychology. Qualitative Research in Psychology, Bristol, v. 3, n. 2, p. 77-101, 2006.

CECCIM, Ricardo B. Onde se lê "Recursos Humanos da Saúde", leia-se "Coletivos Organizados de Produção da Saúde": Desafios para a Educação. In: PINHEIRO, Roseni; MATTOS, Ruben A. (orgs.). Construção social da demanda: direito à saúde, trabalho em equipe, participação e espaço públicos. Rio de Janeiro: Cepesc/ Uerj: Abraso, 2005a. p. 161-180.

CECCIM, Ricardo B. Educação Permanente em Saúde: desafio ambicioso e necessário. Interface: Comunicação, Saúde e Educação, Botucatu, v. 9, n. 16, p. 161-177, 2005b.

CECCIM, Ricardo B.; FEUERWERKER, Laura C. M. O quadrilátero da formação para a área da saúde: ensino, gestão, atenção e controle social. Physis: Revista de Saúde Coletiva, Rio de Janeiro, v. 9. 14, n. 1, p. 41-65, 2004. Disponível em: <http://dx.doi.org/10.1590/S010373312004000100004>. Acesso em: 21 set. 2015

DELEUZE, Giles; GUATTARI, Félix. Mil platôs. vol. 1, Rio de Janeiro: Editora 34, 2011.

DIMENSTEIN, Magda. O psicólogo e o compromisso social no contexto da saúde coletiva. Psicologia em Estudo, Maringá, v. 6, n. 2, p. 57-63, 2001.

ESCÓSSIA, Liliana; KASTRUP, Virgínia. O conceito de coletivo como superação da dicotomia indivíduo-sociedade. Psicologia em Estudo, Maringá, v. 10, n. 2, p. 295-304, 2005.

FIGUEIREDO, Mariana D.; CAMPOS, Rosana O. Saúde mental na atenção básica à saúde de Campinas, SP: uma rede ou um emaranhado? Ciência \& Saúde Coletiva, Rio de Janeiro, v. 14, n. 1, p.129-138, 2009.
HADDAD, Jorge; ROSCHKE, María A. C.; DAVINI, María C. Processo de trabajo y educacion permanente de personal de salud: reorientación y tendencias en America Latina. Educacion Médica y Salud, Washington, D.C., v. 24, n. 2, p. 136-204, 1990.

KASTRUP, Virgínia; PASSOS, Eduardo. Cartografar é traçar um plano comum. Fractal: Revista de Psicologia, Rio de Janeiro, v. 25, n. 2, p. 263-280, 2013. Disponível em: <http:// dx.doi.org/10.1590/S1984-02922013000200004>. Acesso em: 19 out. 2015.

LEITE, Loiva S. Viver fora depois de muito tempo dentro: narrativas de vida de pessoas libertadas. Porto Alegre: Letra \& Vida, 2012.

MERHY, Emerson E.; FRANCO, Túlio B. Por uma composição técnica do trabalho em saúde centrada no campo relacional e nas tecnologias leves: apontando mudanças para os modelos tecnoassistenciais. Saúde em Debate, Rio de Janeiro, v. 27, n. 65, p. 316-323, 2003.

PASSOS, Eduardo; BARROS, Regina D. B. Clínica, política e as modulações do capitalismo. Lugar Comum: Estudos de Mídia, Cultura e Democracia, Rio de Janeiro, n. 19-20, p. 159-171, 2004.

PASSOS, Eduardo; KASTRUP, Virgínia; ESCÓSSIA, Liliana (orgs.). Pistas do Método da Cartografia: pesquisa-intervenção e produção de subjetividade. Porto Alegre: Sulina, 2015.

PELBART, Peter P. A nau do tempo-rei: sete ensaios sobre o tempo da loucura. Rio de Janeiro: Imago, 1993. 132 p.

PINHO, Filipe F.; MOLON, Susana I. Os bastidores do diário de campo: um instrumento de pesquisa qualitativa. In: SEMINÁRIO DE PESQUISA QUALITATIVA, 10., 2011, Rio Grande. Anais..., Rio Grande: Furg, 2011. v. 1. p. 1-11.

ROCHA, Marisa L. Psicologia e as práticas institucionais: a pesquisa-intervenção em movimento. Psico, Porto Alegre, v. 37, n. 2, p. 169-174, 2006. 
ROCHA, Marisa L.; AGUIAR, Kátia F. Pesquisa-intervenção e a produção de novas análises. Psicologia: Ciência \& Profissão, Brasília, v. 23, n. 4, p. 64-73, 2003.

ROMAGNOLI, Roberta C. O conceito de implicação e a pesquisa-intervenção institucionalista. Psicologia \& Sociedade, Porto Alegre, v. 26, n. 1, p. 44-52, 2014.

ROSA, João Guimarães. Grande Sertão: Veredas. São Paulo: Nova Aguilar. 1994. p. 436.

SCARPARO, Helena; LEITE, Loiva S.; SANTOS, Sara J. E. Saúde mental em Porto Alegre: considerações sobre os nossos caminhos. In: LEITE, Loiva S. et al. (orgs.). Saúde Mental ConVida: Registros da trajetória da saúde mental na cidade de Porto Alegre. Porto Alegre: SMS, 2013. p. 140-147.
VIVOT, Claudia C.; OSÓRIO, Elaine A. D. Educação Permanente como dispositivo para a construção de rede de cuidado: o enfrentamento da dengue em Sorocaba (SP). In: L'ABBATE, Solange; MOURÃO, Lucia C.; PEZZATO, Luciane M. (orgs.). Análise institucional \& saúde coletiva. 1. ed. São Paulo: Hucitec, 2013. p. 412-441.

YASUI, Silvio. Rupturas e encontros: desafios da Reforma Psiquiátrica Brasileira. 2006. 208 f. Tese (Doutorado em Ciências na Área da Saúde) - Escola Nacional de Saúde Pública Sergio Arouca, Fundação Oswaldo Cruz, Rio de Janeiro, 2006.

Recebido em 17/02/2016. Aprovado em 03/04/2017. 